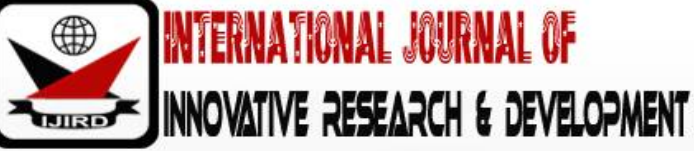

ISSN 2278 - 0211 (Online)

\section{The Impact of National Health Insurance Scheme Policy on the Enrollees in Federal Medical Center Keffi, Nasarawa State, Nigeria}

\author{
Dr. Linda Kwon-Ndung \\ Senior Lecturer, Department of Political Science, Federal University Lafia, Nigeria \\ Obam Okpe Matthew \\ Postgraduate Researcher, Department of Political Science, Nasarawa State University, Keffi, Nigeria
}

\begin{abstract}
:
This study examined the implementation of the National Health Insurance Scheme (NHIS) as a social health insurance on the enrollees in Federal Medical Center Keffi(FMC Keffi) of Nasarawa State, Nigeria to the ascertain the effectiveness of the policy on the enrollees. The survey depended on both primary and secondary sources of information for data for the study. Simple percentage was adopted as the method of data analysis. As at the first quarter of 2018 a total population of 15,086 enrollees drawn from all the Health Maintenance Organizations have Memorandum of Understanding with FMC Keffi, with a monthly encounter average of 1,257. Thus, the sample size was determined by Taro Yamme's model and 390 enrollees were randomly selected for the survey. The study revealed that most enrollees face a wide range of challenges in terms of access to quality healthcare service delivery such as; waiting time to see doctors, non-availability of prescribed drugs, sometime lack of prescription sheets. The challenges of non-availability of drugs is largely due to the prescription of branded drugs especially at Specialist Clinics, which are not covered on NHIS, however for drugs which are covered on the scheme and are not available, FMC Keffi made provision for out-sourcing from nearby pharmacies within 24 hours, for the patients. The management of FMC Keffi, also make refund for out-of-pocket spending to patient who could not wait for the out-sourcing. The study recommends that for the enrollees to effectively benefit from this policy all government hospitals and other private hospitals which meet the requirement should be accredited in order to make access to quality healthcare service delivery reachable and affordable at all times for the enrollees amongst others.
\end{abstract}

Keywords: Health care, enrollees and health maintenance organizations

\section{Introduction}

Social Health Insurance (SHI) is a health sector financing alternative to the cash and carry system that had been in operation in the past. The health burden in countries world over has continued to escalate. The most vulnerable are the poor while the wealthy are the healthier (Ahuja, 2005). This means that where the economic status of the poor could not contain their health needs, the wealthy seem to spend less (in percentage terms) of their income on healthcare needs. One of the basic principles of the World Health Organization (WHO) in the 1946 Constitution states that "the enjoyment of the highest attainable standard of healthcare is one of the fundamental rights of every human being without distinction of race, political belief, geographical location, economic or social condition" (WHO, 2006). This declaration brought to the forefront one of the greatest challenges of governance in this century. It puts on governments the burden of creating and maintaining a healthcare system that will ensure complete physical, mental and social well-being of their peoples. The responsibility of establishing, financing and sustaining a high-profile health system that can facilitate the accomplishment of this noble obligation by governments has never come easy anywhere in the world. These challenges coupled with the fact that national growth is a function of the wellbeing of the citizens; led the then Emperor Otto Vo Bismark of Germany to enact a mandatory law on "sickness funds" in the year 1883, (Awosika, 2005). This "sickness funds" is what is now called Social Health Insurance (SHI) in almost all the countries of the world today.

Japan enacted her own insurance law in 1922 (Ijeomah, 2005). In Britain, the National Health Service Act of 1946 which went into effect in 1948 provided a socialized health care system for all citizens because "citizens were deemed to have a right to free health care regardless of income", (Microsoft Encarta, 2006). By 1970s, nearly all urban Chinese population and $85 \%$ of rural lives had been covered by one form of health insurance or the other, according to World Bank Report, (Meng \& Tang, 2013). The National Health Insurance Scheme was implemented in Taiwan, in 1995, (Lee, 2010) and in 1996; the Government of Tanzania initiated the Community Health Insurance Scheme with the aim of improving access to health care, (Ahuja \&Jutting,2004). For our own "Giant of Africa", Nigeria, the scheme did not take off until 2005 even though the idea was muted as far back as 1962. The actual promulgation of the enabling legislation, Degree 35 of 
1999 became the first major government commitment that facilitated the schemes eventual take off, six years later (Awosika, 2005).

The principal aim is to reduce the high dependency on Out- Of-Pocket (OOP) payments in the form of user charges and co-payments, which are regressive as they excessively, affect the poor in society, and therefore challenge the underlying belief of equity within healthcare systems (Ezeoke, Onwujekwe \& Uzochukwu, 2012). The development of the National Health Insurance Scheme (NHIS) in Nigeria dates back to the post-independence era of 1962 (Metiboba, 2011). The government at the outset funded universal and free health care in largely public facilities using revenues from oil exports and general taxation. However, the global fall in oil prices in the 1980s meant that the Government could no longer have enough money to provide free health care. Several cost recovery mechanisms based on Out-of-Pocket (OOP) charges were introduced in conjunction with a growth in the privatization of health care (Falegan, 2008). In addition, the introduction of the Structural Adjustment Programme in 1986 reduced the health sector budget.

Additional pressures that led to the introduction of the NHIS included: (a) the general poor state of the nation's health care services, (b) the undue reliance and demands on government-provided health facilities, (c) diminishing funding of health care in the face of rising costs, and (d) poor incorporation of private health facilities in the nation's health care delivery system. In terms of implementation (Ibiwoye, 2008), the National Council on Health (NCH) approved repackaging to ensure full private sector participation in the scheme and legislation was signed in May, 1999. The NHIS of Nigeria came into full operation in 2005. Its principal aim is to secure 'universal coverage and access to adequate and affordable healthcare in order to improve the health status of Nigerians, especially for those participating in the various programmes/ Products of the Scheme.

Partly because of the phased implementation of the NHIS in Nigeria, eighteen (18) years into the introduction of the scheme, enrolment appears to be rather very slow as only Federal Civil Servants Military and Para-military are fully registered into the scheme in the Formal Sector Health Insurance Programme (FSHIP) aspect, and majority of Healthcare Providers are situated in the urban centers which could affect quick accessibility to satisfactory healthcare service especially those who are outside their location.

Also, most NHIS services are tied to the general service of many hospitals without any form of independence, especially in areas of drugs dispensaries and revolving funds. The inability of the healthcare consumers to choose or change their Health Maintenance Organization (HMO) even if thereis service failure in securing secondary referral authorization codes for secondary healthcare services, posed a great challenge to the operations of NHIS to her enrollees as well as negate the fundamental objectives of the scheme.

Federal Medical Centre Keffi (FMCK) is registered as Primary, Secondary and Tertiary Healthcare provider with the scheme. At inception in 2005, the centre had just 350 enrollees, which have increased from 8,000 in 2015 to 12,000 in 2016 (FMCK, 2016) and 15,086 first quarter 2018. FMC Keffi in line with directive from NHIS management, signed Memorandum of Understanding (MoU) with Nagari Allah Magani Hospital, Keffi in 2015 as Alternative Healthcare Provider (AHP) in case of any industrial action, which has not been evaluated. This study seeks to examine the impact of NHIS on its enrollees and to ascertain the quality of service delivery in terms of access to quality medi-care of its enrollees

\section{Research Methodology}

\subsection{Research Design}

The research is exclusively a survey research which was set out to assess NHIS in line with its policy on healthcare service delivery to Nigerians. Respondents are NHS enrollees in FMC Keffi, and patients who attended NHIS Clinic at the time of administering the questionnaire.

\subsection{Population, Sample and Sampling Techniques}

The population of study was drawn from entire NHIS enrollees, as well as staff of FMC Keffi who choose FMC Keffi as their Primary Healthcare Facility (HCF), a total of 15,086 (first quarter 2018 Panel List) and other secondary referral clients which comprises of all formal sector employees whose Health Maintenance Organization (HMO) have Memoranda of Understanding (MOU) with FMC Keffi. The population also includes FMC staff in the NHIS Unit.

\begin{tabular}{|c|c|c|c|}
\hline No & Health Maintenance Organization & Hmo Code & Total Enrollee \\
\hline 1 & AIICO Multishield Nigeria Limited & 006 & 340 \\
\hline 2 & Avon Healthcare Limited & 063 & 60 \\
\hline 3 & Clearline International Limited & 003 & 426 \\
\hline 4 & Health Care Security & 024 & 01 \\
\hline 5 & Healthcare International Limited & 004 & 7,638 \\
\hline 6 & Hygeia HMO Limited & 001 & 236 \\
\hline 7 & Int'l Health Mgt. Services & 011 & 35 \\
\hline 8 & Integrated Healthcare & 014 & 322 \\
\hline 9 & Maayoit Healthcare Limited & 018 & 33 \\
\hline 10 & Managed Healthcare Services Ltd & 016 & 423 \\
\hline 11 & Markfema Nigeria Ltd. & 029 & 33 \\
\hline 12 & Mediplan Healthcare Limited & 005 & 116 \\
\hline 13 & NHIS CUSTOMS & 080 & 101 \\
\hline
\end{tabular}




\begin{tabular}{|c|c|c|c|}
\hline No & Health Maintenance Organization & Hmo Code & Total Enrollee \\
\hline 14 & Nonsuch Medicare Limited & 051 & 113 \\
\hline 15 & Novo Health Africa Limited & 074 & 36 \\
\hline 16 & Oceanic Health Management Limited & 039 & 07 \\
\hline 17 & Police Health Maintenance Limited & 073 & 1,446 \\
\hline 18 & Precious Healthcare Limited & 036 & 148 \\
\hline 19 & Premier Medicaid & 015 & 562 \\
\hline 20 & Princeton Health & 017 & 46 \\
\hline 21 & Prohealth Hmo & 057 & 01 \\
\hline 22 & Regenix Health Care Service Limited & 064 & 10 \\
\hline 23 & Ronsberger Nigeria Ltd. & 010 & 60 \\
\hline 24 & Royal Exchange Healthcare Limited & 046 & 12 \\
\hline 25 & Songhai Health Trust & 013 & 228 \\
\hline 26 & Total Health Trust Limited & 002 & 454 \\
\hline 27 & Ultimate Health Management Services Ltd & 061 & 180 \\
\hline 28 & United Comprehensive Health Managers Ltd & 023 & 35 \\
\hline 29 & United Healthcare International Limited & 007 & 1,016 \\
\hline 30 & Venus Medicare Ltd & 021 & 396 \\
\hline 31 & Wetlands Health Services Ltd & 020 & 96 \\
\hline 32 & Wise Health & 019 & 09 \\
\hline 33 & Zuma Health Trust & 028 & 25 \\
\hline 34 & Defence HMO & 022 & 442 \\
\hline & TOTAL & & 15,086 \\
\hline
\end{tabular}

Table 1

Sources: Field Survey, 2018

FMC Keffi as at First Quarter 2018 has a total population of 15,086 enrollees drawn from all the HMOs who have Memorandum of Understanding with FMC Keffi, with a monthly encounter average of 1,257 (NHIS 1st Quarter Panel List). Thus, the sample size was determined by Taro Yamme's model and 390 is arrived at the sample size.

\subsection{Method of Data Collection}

The study used both primary and secondary sources of data. The primary data was the leading source of data collection this include; questionnaire, which was obtained during patient daily encounter at the NHIS Clinic.

\subsection{Techniques for Data Analysis}

The research used simple random sampling techniques in the collection of data relevant for the study, especially in the administration of questionnaire. Meanwhile simple percentage was used for the data analysis.

\begin{tabular}{|c|c|c|}
\hline Categories & Returned & Percentage of Returned \\
\hline Non-Retrieved & 43 & 11.02 \\
\hline Non-Valid & 29 & 7.44 \\
\hline Valid & 318 & 81.54 \\
\hline TOTAL & 390 & 100 \\
\hline
\end{tabular}

Table 2: Questionnaire Collated Table Source: Field Survey 2018

The above table shows questionnaire collated table, where non-retrieved questionnaire stands at $11.02 \%$, while non-valid is $7.44 \%$ and Valid amounts to $81.54 \%$ (approximately $82 \%$ ) of total questionnaire administered. Thus, according Osuala (2003), 70\% valid response is enough to generalize the response of others, therefore 318 (82\%) is enough to work with in this research.

\begin{tabular}{|c|c|c|}
\hline Gender & Frequency & Percentage (\%) \\
\hline Male & 91 & 28.62 \\
\hline Female & 227 & 71.38 \\
\hline TOTAL & 318 & 100 \\
\hline \multicolumn{3}{|c|}{ Table 3: Genders of Enrollees } \\
Source: Field Survey, 2018
\end{tabular}

The table above shows the gender of the respondents whose opinions were acquired during the field work. Ninety-one (91) respondents which represent $29 \%$ male, while female respondents are Two Hundred and Twenty-seven (227) which represents $71 \%$ of the total respondent. This percentage of the female respondents shows that more women 
accessed care more than male counterpart and are more likely to bring the children to the hospital or takes care of the sick dependents.

\begin{tabular}{|c|c|c|}
\hline Categories (in Years) & Frequency & Percentage (\%) \\
\hline $1-3$ & 50 & 15.72 \\
\hline $4-6$ & 102 & 32.08 \\
\hline $7-9$ & 86 & 27.04 \\
\hline $10-13$ & 80 & 25.16 \\
\hline TOTAL & 318 & 100 \\
\hline
\end{tabular}

Table 4: Number of Years Respondents Had Been on NHIS Sources: Field Survey, 2018

Table 4 show the number of years an enrollee has been on NHIS. 50 (15.72\%) have been on NHIS between 1-3 years, $102(32.08 \%)$ are on NHIS between 4-6 years while 86 (27.04\%) enrollees are on NHIS for 7-9 years and 80 (25.16\%) have been on NHIS between 10-13years. Therefore, 268 (84.28\%) have been of NHIS between 4-13 years which covers the period in which the study is undertaken as such provide a valid response for the study.

\begin{tabular}{|c|c|c|}
\hline Categories (in Years) & Frequency & Percentage (\%) ) \\
\hline $0-3$ & 55 & 17 \\
\hline $4-6$ & 105 & 33 \\
\hline $7-9$ & 98 & 31 \\
\hline $10-13$ & 60 & 19 \\
\hline TOTAL & 318 & 100 \\
\hline
\end{tabular}

Table 5: Numbers of Years Using FMC Keffi (As Health Care Provider) Sources: Field Survey, 2018

Table 1.4 shows the number of year's enrollees has been in FMC Keffi as their Primary Healthcare Provider. 55 (15.72\%) enrollees have been in FMC Keffi between 0-3 years, This category constitute those that got employment in recent times, those who only got their registration papers recently and those who have transferred from their former HCPs either because of change of location or because of enrollee dissatisfactions, 105 (33\%) are in FMC Keffi between 4-6 years while 98 (31\%) enrollees are in FMC Keffi between 7-9 years and 60 (19\%) have been in FMC Keffi between 10-13years. Therefore, $263(82.70 \%)$ have been in FMC Keffi between 4-13 years which covers the period in which the study is undertaken as such provide a valid response for the study.

\begin{tabular}{|c|c|c|}
\hline Variables & Frequency & Percentage (\%) \\
\hline 4 & 261 & 82.07 \\
\hline 5 & 57 & 17.93 \\
\hline TOTAL & 318 & 100 \\
\hline
\end{tabular}

Table 6: Numbers of Dependable Registrants on NHIS

Sources: Field Survey, 2018

The above table shows that 261 of the respondents, representing $82.07 \%$ rightly indicated that NHIS allows for the registration of four (4) biological children although the allowed age limit is below eighteen years. While 57 respondents, representing $17.93 \%$ did not have the knowledge of the number allows for registration, however they could have missed extra-dependents as part of the number.

\begin{tabular}{|c|c|c|}
\hline Variables & Frequency & Percentage (\%) \\
\hline 18 Years & 277 & 87.11 \\
\hline 19 Years & 41 & 12.89 \\
\hline TOTAL & 318 & 100 \\
\hline
\end{tabular}

Table 7: Age Limit for Children on NHIS Sources: Field Survey, 2018

The above table sought to investigate if NHIS enrollees have knowledge of age limit of children on NHIS, which is 18 years. The outcome shows that, 277 respondents which represent $87.11 \%$ said 18 years, while $12.89 \%$ of 41 respondents said 19 years. This therefore shows that majority of NHIS enrollees are aware of age limit on NHIS

\begin{tabular}{|c|c|c|}
\hline Variables & Frequency & Percentage (\%) \\
\hline Yes & 301 & 94.65 \\
\hline No & 17 & 5.35 \\
\hline Total & 318 & 100 \\
\hline
\end{tabular}

Table 8: Awareness of NHIS Exclusion List Sources: Field Survey, 2018 
The above table 8 shows the responses that aware about NHIS Exclusion List. 301 respondents representing 94.65\% are aware of NHIS Exclusion List, while 17 respondents representing 5.35\% are not aware of NHIS Exclusion List.

\begin{tabular}{|c|c|c|}
\hline Variables & Frequency & Percentage (\%) ) \\
\hline Family planning implants & 281 & 88.36 \\
\hline $\begin{array}{c}\text { Medical Check-up unrelated to } \\
\text { illness }\end{array}$ & 37 & 11.66 \\
\hline Total & 318 & 100 \\
\hline
\end{tabular}

Table 9: Items on the NHIS Exclusion List

Sources: Field Survey, 2018

The table above was created to further re-enforce enrollees' awareness of NHIS operations guideline in relations to Exclusion List. The result shows that, they are aware of NHS exclusion list; however, 281 which represent 88.36 of the respondents are aware of Family Planning Implants (commodities, such as condoms). This further validates that enrollees accessed healthcare service.

\begin{tabular}{|c|c|c|}
\hline Variables & Frequency & Percentage (\%) \\
\hline CT SCAN & 199 & 62.57 \\
\hline HSG & 73 & 22.96 \\
\hline MRI & 46 & 14.47 \\
\hline Total & 318 & 100 \\
\hline
\end{tabular}

Table 10: Co-Payment for Drugs and Other Services

Sources: Field Survey, 2018

The above table explained the rate of awareness of NHIS Co-payment for other services or procedures apart from drugs. The results show that; 199 Respondents which represent $62.57 \%$ are aware of the co-payment of CT-Scan, while 73 Respondent representing 22.96\% are aware of HSG and 46 Respondents representing $14.47 \%$ are aware of MRI copayment on NHIS. The outcome is largely due to which of the investigation respondents could have undertaken on the scheme.

\begin{tabular}{|c|c|c|}
\hline Variables & Frequency & Percentage (\%) \\
\hline Once & 18 & 5.66 \\
\hline Twice & 32 & 10.06 \\
\hline Thrice and above & 268 & 84.27 \\
\hline TOTAL & 318 & 100 \\
\hline
\end{tabular}

Table 11: Frequency of Access to NHIS in a Year Sources: Field Survey, 2018

The Table 11shows that, 18 respondents have accessed healthcare services on NHIS once a year, while 32 $(10.06 \%)$ accessed healthcare services twice in a year and 268 which represent $84.27 \%$ accessed healthcare service under NHIS more than three times in a year. These responses validate the table 4.1.2 as earlier stated.

\begin{tabular}{|c|c|c|}
\hline Variables & Frequency & Percentage (\%) \\
\hline Consultation with Doctors & 118 & 37.11 \\
\hline Surgical Operations & 5 & 1.57 \\
\hline Laboratory Test Services & 81 & 25.47 \\
\hline Admission in the Ward & 10 & 3.14 \\
\hline Pharmaceutical Care & 85 & 26.73 \\
\hline Referral to Specialist Clinic when needed & 19 & 5.97 \\
\hline TOTAL & 318 & 100 \\
\hline
\end{tabular}

Table 12: Service(S) Enjoyed on NHIS

Sources: Field Survey, 2018

The above table shows the outcome services that enrollees have enjoyed on NHIS. Consultation with Doctors have the highest number of Respondents of 118 representing 37.11\%, closely followed by Pharmaceutical services with 85 (26.73\%) respondents and Laboratory Services of 81 respondents representing 25.47\%. These shows that those who consult Doctors are most likely to fill drugs prescriptions and or undergo laboratory test for further treatment.

The table also shows that surgical operations constitute 5(1.57\%) respondents, while 10 (3.14\%) respondents have been admitted in the Wards and 19 (5.97) of the respondents have enjoyed referral to specialist clinics. 


\begin{tabular}{|c|c|c|}
\hline Variables & Frequency & Percentage (\%) \\
\hline Waiting time to see Doctors & 128 & 40.25 \\
\hline Congestion at pay point & 72 & 22.64 \\
\hline $\begin{array}{c}\text { Non-availability of prescribed } \\
\text { Drugs }\end{array}$ & 83 & 26.10 \\
\hline $\begin{array}{c}\text { Non-availability of reagent at the } \\
\text { Lab }\end{array}$ & 35 & 11.01 \\
\hline Total & 318 & 100 \\
\hline
\end{tabular}

Table 13: Types of Challenge (S) in Accessing Healthcare Services Source: Field Survey, 2018

The above table 13 shows the various degrees of challenges experienced by the NHIS enrollees in accessing Healthcare service at Federal Medical Centre, Keffi. The respondents show that 128 (40.25\%) mostly experienced challenges that have to do with waiting time to see doctors, 72 (22.64\%) experienced congestion at pay point, meanwhile, for non-availability of prescribed drugs 83 responded which represents $83 \%$ complained of such challenges.

Furthermore, for non-availability of reagents at the laboratory 35 (11.01\%) respondents complained of such challenges and this unabated challenge has adverse effect on patients.

\begin{tabular}{|c|c|c|}
\hline Variables & Frequency & Percentage (\%) \\
\hline YES & 59 & 18.55 \\
\hline NO & 259 & 81.45 \\
\hline Total & 318 & 100 \\
\hline
\end{tabular}

Table 14: Challenges Enough for You to Opt Out of NHIS? Sources: Field Survey, 2018

The above table 14 shows the various degrees of challenges experienced by the NHIS enrollees in accessing Healthcare service at Federal Medical Centre, Keffi is not enough for the enrollees to opt out of the NHIS programme. The respondents show that 259 (81.45\%) says NO. That is to say that with the challenges most of the NHIS enrollees are still okay with the programme.

\begin{tabular}{|c|c|c|}
\hline Variables & Frequency & Percentage (\%) \\
\hline YES & $\mathbf{2 0 5}$ & $\mathbf{6 4 . 4 7}$ \\
\hline NO & 113 & 35.53 \\
\hline TOTAL & 318 & 100 \\
\hline
\end{tabular}

Table 15: The Alternative Healthcare Provider Of NHIS Source: Field Survey, 2018

The table above shows that 205 respondents representing $64.47 \%$ are aware of the Alternative Healthcare provider policy of FMC Keffi, during industrial actions (strike), while 113 respondents representing $35.33 \%$ are not aware of the policy. To this end, the management of FMC Keffi should create more awareness program of the policy especially during clinic to the patients.

\begin{tabular}{|c|c|c|}
\hline Variables & Frequency & Percentage (\%) \\
\hline Yes & 198 & 62.26 \\
\hline No & 120 & 37.74 \\
\hline Total & 318 & 100 \\
\hline
\end{tabular}

Table 16: Assessment of Alternative Healthcare Provider, During Industrial Actions Source: Field Survey, 2018

The above table 16 shows that, 198 (62.26\%) respondents have accessed healthcare service at the Alternative Healthcare Provider, when FMC Keffi was on strike, while 120 (37.74\%) have not accessed healthcare services during strike.

\begin{tabular}{|c|c|c|}
\hline Variables & Frequency & Percentage (\%) \\
\hline Satisfactorily & 103 & 52.02 \\
\hline Not Satisfied & 55 & 27.78 \\
\hline Indifference & 40 & 20.20 \\
\hline Total & 198 & 100 \\
\hline
\end{tabular}

Table 17: Satisfactions of Healthcare Consumers at

Alternative Providers

Field Survey, 2018 
Out of the 198 respondents who accessed healthcare services at the Alternative Healthcare Provider, when FMC Keffi was on strike, 103 representing $52.02 \%$ were satisfied with the services they received at the Alternative Healthcare Provider, while $55(27.78 \%)$ respondents are not satisfied and $40(20.20 \%)$ are indifference with the services they received.

\section{Conclusion}

The introduction of the National Health Insurance Scheme in the year 2005, has indeed created opportunity for a number of Nigerian Federal civil servants and the other security outfits and private organization to access medical care in Federal Medical Centre Keffi although the enrollees are paying 5 percent (5\%) of their basic salary at all levels as a contribution to the pool for onward healthcare service delivery.

Apparently, there are a number of challenges faced by most enrollees in terms of access to quality healthcare service delivery as revealed by the study, these include; waiting time to see doctors, non-availability of prescribed drugs, sometime lack of prescription sheets. However, the efforts of the management of FMC Keffi to provide funds within 24 Hrs for out sourcing of drugs in hereby pharmacy is no doubt an attempt to ensure that the enrollees get the desired medical attention but a lot needs to be done in order to ensure the effective implementation of the health insurance policy in FMC Keffi and by extension Nigeria at large.

\section{Recommendations}

To address the challenges revealed by the study and to attain the desired quality of healthcare service delivery and the management of the National Health Insurance Scheme (NHS)., the following recommendations are made for the future improvement in health management in Nigeria as enshrined in the National Health Insurance Scheme policy of 1999 and its implementation since 2005 to date.

- Federal government should ensure every Nigerian have access to good health care services at affordable cost; with availability of drugs in all government own hospitals.

- Federal government should build NHIS block for hospitals in order to overcome the challenges of insufficient consulting room and reduction in waiting time for consultations in ensuring efficiency in healthcare services.

- Improve and harness private sector participation in the provision of healthcare services to all Nigerians and ensure the availability drugs in the NHISpharmacy.

- Ensure adequate recruitment and deployment of medical Doctors to address the challenge of long time of waiting by enrollees in FMC Keffi

- Government hospitals and other private hospitals that meet up with the required standard should be accredited in order to make access to quality healthcare service delivery reachable and affordable at all times for the enrollees

- (vi)Ensure the availability of prescription sheets to facilitate the smooth and prompt services and equitable distribution of health facilities within FMC Keffi and the federation at large.

\section{References}

i. Ahuja, R. (2005). - Health Insurance for Poor: An analytical Study. || Indian Council for Research on International Economic Relations Working Paper no. 161.

ii. Ahuja, R.\& J. Jütting (2004). Are the Poor Too Poor to Demand Health Insurance. Journal of Microfinance/ ESR Review 6(1).

iii. Awosika, L. (2005) "Health Insurance and managed care in Nigeria", Annals of Ibadan Postgraduate Medicine. Vol 3 No. 2

iv. Ezeoke, O. P., Onwujekwe, O. E. \& Uzochukwu, B. S. (2012): Towards Universal Coverage: Examining Costs of Illness, Payment, and Coping Strategies to different population groups in Southeast Nigeria. The American journal of tropical medicine and hygiene,

v. Federal Ministry of Health (FMOH) (1998). Policy and strategy to achieve health for all Nigerians. Lagos: Federal Ministry of Health.

vi. Federal Medical Centre Keffi. (2016). 2016 Annual Report.

vii. Gana, D. (2010). Roles of the healthcare Provider in Health Insurance. Nigeria Medical Association Annual Conference Paper.

viii. Health Care Consumers Association (1998). Who is a Health Care Consumer? Accessed via: Http:/ / www.hcca.org.au/ index.php/ consumers.html 25th June, 2017

ix. Health Consumers Society (1991). Who is a Health Consumer? Accessed via: http:// www.hcnsw.org.au/ pages/who-is-a-health-consumer-and-other-definitions.html June, 25th 2017.

x. Ibiwoye, A. \&Adeleke, A., (2008) "Does National Health Insurance Promote Access to quality Health Care? Evidence from Nigeria" The General papers on Risk Insurance - $\quad$ issues and practice 33, 219-233

xi. Ijeomah, L.A., (2005) "Introducing social Health Insurance to solve problems of poor Health Sector Financing in Nigeria" Journal of Health College of Medicine 3.2.97-99

xii. Lee, P. (2010). The Impact of Universal National Health Insurance on Population Health: The Experience of Taiwan. Accessed via http:// bmchealthservres.biomedcentral.com/articles/10.1186/1472-6963-10-225 $15^{\text {th }}$ March, 2017.9:10pm

xiii. Meng, Q. \& Tang, S. (2013). Universal Health Care Coverage in China: Challenges and Opportunities ProcediaSocial and Behavioral Sciences, 77 (0) (2013) 
xiv. Mercy, A. (2017). Healthcare International HMO 2017 Interactive Session with FMC Keffi Enrollees in Federal Medical Centre, Keffi.

xv. Merton, R.K. (1968). Social Theory and Social Structure. Rev. Ed. New York: Free Press. National Health Insurance Scheme (2009). Annual Report. National Health Insurance Scheme Abuja, Nigeria, 4-35.

xvi. National Health Insurance Scheme (2012). Annual Report. National Health Insurance Scheme Abuja, Nigeria.

xvii. World Health Organization (2006). The World Health Report 2006 - Working Together for Health. Accessed via: http:/ / www.who.int/ whr/ 2006/ en/ 